\title{
ОТСРОЧКА ОТБЫВАНИЯ НАКАЗАНИЯ БОЛЬНЫМ НАРКОМАНИЕЙ И ВОПРОСЫ ЕЕ ПРИМЕНЕНИЯ
}

\begin{abstract}
Аннотация: В статье подробно проанализированы признаки субъекта наркопреступления, на которого распространяются положения об отсрочке отбывания наказания больным наркоманией, предусмотренные ст. 82.1 УК. В результате сравнительного исследования названной нормы уголовного закона выявлены существенные отступления от предписаний Стратегии государственной антинаркотической политики Российской Федерации до 2020 года в части предлагавшихся уголовно-правовых мер по сокращению незаконного распространения и немедицинского потребления наркотиков. Раскрыта сущность медико-правового несоответствия в понятиях «наркомания» и «токсикомания» российского законодательства и вытекающих из требований Международного классификатора болезней 10 пересмотра (МКБ-10) законодательства западных стран. Показано как нормативная практика Правительства РФ по формированию списков наркотиков определяет нестабильность поставленного диагноза «наркомания» и возможность его трансформачии в «токсикоманию» и наоборот, тем самым ограничивая пределы применения ст. 82.1 УК видом злоупотребляемого психоактивного вещества. На примере рассмотрения отдельных проблемных вопросов реализачии нового уголовно-правового института отсрочки отбывания наказания больным наркоманией наркопреступников, в том числе и в уголовно-процессуальном аспекте, предложены рачиональные пути его совершенствования.

Ключевые слова: Юриспруденция, наркотические средства и психотропные вещества, сильнодействующие и ядовитые вещества, психоактивные вещества, наркомания и токсикомания, наркоинфицированный, обязательное лечение, наркопреступления, наркостатьи, антинаркотический
\end{abstract}

B качестве генеральной цели и одного из направлений Стратегии государственной антинаркотической политики РФ до 2020 года (далее - Стратегия), утвержденной Указом Президента РФ № 690 от 9 июня 2010 года, было названо существенное сокращение незаконного распространения и немедицинского потребления наркотиков. Реализация поставленной цели предполагала введение норм о предоставлении подсудимым, больным наркоманией и признанным виновными в совершении преступлений небольшой или средней тяжести, связанных с незаконным оборотом наркотиков и их прекурсоров, возможности выбора между лечением и уголовным наказанием, а также установлении механизма контроля принятых обязательств по лечению и ответственности за их невыполнение (п. 43).

Как можно видеть, Стратегией не планировалось возрождение уголовно-правового института принудительного лечения больных наркоманией, токсикоманией или алкоголизмом. Предусматривалась лишь возможность подвергнуть совершившего наркопреступление больного наркоманией по приговору суда добровольному обязательному лечению как альтернатива назначения ему наказания. Кстати заметить, в году принятия Федерального закона от 08.12.2003 г. № 162-Ф3, которым отменялись принудительные меры медицинского характера в отношении больных наркоманией, принудительное лечение от наркомании было назначено 12671 лицам. ${ }^{1}$

К субъектам, на которых согласно предписаниям Стратегии должны были распространяться нормы об обязательном лечении, относились больные наркоманией подсудимые, совершившие наркопреступления из категории не выше средней тяжести. То есть предусмотренные ч.1 ст. $228,228.2$, ч.1 ст. 230 , ч.1 ст. 231, ч.1 ст. 232, 233, ч.1, 2, 4 ст. 234 УК. Причем, никаких ограничений по видам назначаемого наказания, которые могли бы подлежать замене, Стратегией не предусматривалось. И это важно, поскольку санкции указанных статей включают штраф, обязательные работы, исправительные работы, ограничение свободы, лишение свободы, обязательные работы с лишением права занимать определенные должности или заниматься определенной деятельностью, арест, принудительные работы с лишением права занимать определенные должности или заниматься определенной деятельностью, лишение свободы с лишением права занимать определенные должности или заниматься определенной деятельностью.

\footnotetext{
1 Здесь и далее приведены данные Судебного департамента при Верховном Суде РФ. [Электронный ресурс]. - Режим доступа: http://crimpravo.ru/page/sudstatistic/.
} 


\section{Право и политика $5(161) \cdot 2013$}

Названные положения Стратегии впоследствии получили развитие в Федеральном законе от 07.12.2011 г. № 420-Ф3 о дополнении уголовного кодекса ст. 82.1 «Отсрочка отбывания наказания больным наркоманией», которой были определены основы нового уголовно-правового института. Однако по своему содержанию данная статья оказалась принципиально отличной от соответствующих предписаний Стратегии, более универсальных в своей антинаркотической направленности. И главным здесь видится то, что нормой об отсрочке отбывания наказания установлена иная совокупность признаков, которым должен отвечать субъект, подлежащий обязательному лечению.

И таким субъектом выступает лицо, которое

1) осуждено к лишению свободы;

2) признано больным наркоманией;

3) совершило впервые преступление, предусмотренное ч. 1 ст. 228 , ч.1 ст. 231 и ст. 233 УК;

4) изъявило желание добровольно пройти курс лечения от наркомании, а также медико-социальную реабилитацию.

Первые три признака являются объективными, а последний следует отнести к субъективному, поскольку его наличие определяется усмотрением самого осужденного.

Рассмотрим каждый из признаков в отдельности и попытаемся выявить особенности исследуемой нормы и тем самым определить пределы ее применения.

1. Распространение законодательных требований об отсрочке наказания на лиц, осужденных к лишению свободы (в Стратеги - подсудимых), означает, что вопрос о применении положений ст.82.1 УК подлежит разрешению, только если одновременно будет

- вынесен обвинительный приговор,

- назначено наказание в виде лишения свободы,

- наказание суд постановит отбывать реально.

Соответственно, не установление вины подсудимого в инкриминируем преступлении и вынесение судом оправдательного приговора, по которому лицо приобретает уголовно-процессуальный статус оправданного, рассмотрение вопросов, связанных с лечением наркомании, автоматически исключает. То есть, никаких обязанностей по поводу последующего лечения от наркомании, отказ или уклонение от которого означает продолжение потребления наркотиков, на оправданного судом больного наркоманией не возлагается.

В данной связи вообще представляется сомнительным перенос принятия решения об обязательных мерах медицинского характера на стадию вынесения приговора. Получается, что в течении многих месяцев предварительного следствия и судебного разбирательства страдающий наркоманией виновный, в отношении которого избрана иная, нежели арест, мера пресечения (подписка о невыезде, залог и т.д.), никакими обременениями (например, в виде законодательно обеспеченного обязательства не потреблять наркотики) по поводу своей болезни со стороны государства в лице органов предварительного расследования, прокуратуры и суда, подвергаться не может. Думается, что с подобной пассивностью государства в данном вопросе согласиться нельзя.

Не подлежит рассмотрению вопрос об обязательном лечении от наркомании в случае, если суд назначит иное, не связанное с лишением свободы, наказание. Полагаем, что полномочия суда в части возложения обязанностей по лечению тяжкого заболевания не должны зависеть от вида назначаемого им наказания, если основным здесь является побуждение лица к обязательному лечению. Например, прохождение курса обязательного лечения и медико-социальной реабилитации в период исполнения наказания в виде исправительных или принудительных работ будет только способствовать целям закрепления антинаркотических установок. Ведь приобретение или восстановление утраченных трудовых навыков, формирование трудовой психологии является важнейшей составляющей восстановительной социализации, и государство обязано использовать для этого весь имеющийся законодательный ресурс.

Не применимы положения ст.82.1 УК при назначении наказания в виде лишения свободы, если суд придет к выводу о возможности исправления осужденного без реального отбывания наказания и постановит считать назначенное наказание условным. В данном случае суд будет руководствоваться положениями ст. 73 УК, в соответствии с которыми он устанавливает испытательный срок на период не более 5 лет и возлагает на условно осужденного обязанность пройти курс лечения не только от наркомании, но и от токсикомании, алкоголизма или венерического заболевания. В 2009 г. обязанности пройти курс лечения от алкоголизма были подвергнуты 1239 человек, и 1111 человек - от наркомании. В то же время, из 42336 человек, которым назначено лишению свободы условно за совершение преступлений, предусмотренных ст. 228 УК, обязательное лечение определено 1061 лицам.

2. Больным наркоманией, согласно ст.1 Федерального закона «О наркотических средствах и психотропных веществах» (далее - Закон), признается «лицо, которому по результатам медицинского освидетельствования, проведенного в соответствии с настоящим Федеральным законом, поставлен диагноз «наркомания»». Этой же статьей наркомания определена как «заболевание, обусловленное зависимостью от наркотического средства или психотропного вещества» (далее - наркотики).

Как следует из положений Закона, понятие «наркомания» является медико-юридическим, поскольку определяемое им заболевание диагностируется в зависимости от вида злоупотребляемого вещества. И если заболевание обусловлено злоупотреблением любых иных, не из списка 
наркотиков веществ, то ставится диагноз «токсикомания». К таким веществам относятся различные препараты бытовой и промышленной химии (ацетон, бензин, растворители, очистители, лаки, клеи, краски, пятновыводители и др.), лекарственные препараты (транквилизаторы, снотворные и др.), сильнодействующие (ст.234 УК) и другие аналогичные природные и синтетические вещества.

Из медико-правовой природы рассматриваемого заболевания следует нестабильность поставленного диагноза и возможность его трансформации в токсикоманию и наоборот, что определяется нормативной практикой Правительства РФ по формированию списков наркотиков. Например, постановлением Правительства РФ от 22.02.2012 г. №144² сильнодействующее вещество «гаммабутиролактон» было исключено из одноименного списка веществ и включено в перечень психотропных веществ (Список III). Поэтому с момента вступления данного постановления в силу, злоупотребление указанным веществом следует диагностировать как наркомания с автоматическим наделением осужденного правом на отсрочку от отбывания наказания в порядке ст.82.1 УК, которого он был ранее лишен в связи с диагностированным заболеванием токсикоманией. То есть право на замену уголовного наказания лечением является производным от вида заболевания, определяемого по результатам проведения судебно-наркологической экспертизы. Подобные нормы представляются в некотором смысле стимулирующими, поскольку заключают в себе «выгоду» быть потребителем наркотиков, нежели любых иных наркотикодействующих препаратов. Ведь в случае привлечения потребителя наркотиков к уголовной ответственности он наделяется правом выбирать отбытие наказания или пройти курс обязательного лечения, в то время как больные токсикоманией или алкоголизмом таким правом не обладают. Несоответствие в уголовно-правовых последствиях для страдающих тождественными видами заболеваний разумным признать нельзя, учитывая, что при вынесении приговора об условном лишении свободы возможность назначения обязательного лечения не зависит от вида злоупотребляемого вещества.

Установление законодательных пределов действия нормы ст. 82.1 УК в зависимости от вида злоупотребляемого вещества выглядит сомнительным, поскольку международное право и медицинская наука давно исходят из единых представлений о природе данных веществ и обуславливаемых ими заболеваний. И основным нормативным источником здесь выступает

\footnotetext{
2 Постановление Правительства Российской Федерации от 22.02.2012 г. №144 «О внесении изменений в некоторые акты Правительства Российской Федерации в связи с совершенствованием контроля за оборотом наркотических средств, психотропных веществ и их прекурсоров» // РГ. 6.03.2012 г. №48.
}

Международный классификатор болезней 10 пересмотра (МКБ-10, 1994 г.) $)^{3}$, принятый согласно рекомендациям Всемирной организации здравоохранения. В МКБ-10, пожалуй, впервые на международном уровне было раскрыто универсальное значение веществ, употребление которых нарушает нормальное протекание психических процессов и способствует развитию болезненной психофизиологической потребности в их последующем приеме. Данные вещества и продукты на их основе, применяемые намеренно для изменения психического состояния и способные привести к развитию зависимости (наркомании или токсикомании), в медицине получили общее название психоактивные ${ }^{4}$ (далее - ПАВ). Виды (классы) таких веществ представлены в разделе F1 «Психические и поведенческие расстройства вследствие употребления психоактивных веществ». Их группировка произведена по медицинским критериям, исходя из клинических групп симптомов или поведенческих признаков заболеваний, обусловленных их употреблением. Так, под шифром F10 значатся психические и поведенческие расстройства, вызванные употреблением алкоголя; F11 - опиоидов; F12 - каннабиоидов; F13 - седативных или снотворных средств; F14 - кокаина; F15 - других стимуляторов (включая кофеин); F16 - галлюциногенов; F17 - табака; F18 - летучих растворителей; F19 - одновременным употреблением нескольких наркотических средств и использованием других психоактивных веществ.

Существующая практика разделения анализируемых болезней на наркоманию и токсикоманию выглядит искусственной, и подчеркивает медико-правовое несоответствие между отношением к проблеме злоупотребления веществами в России и других странах Европы и Северной Америки. ${ }^{5}$ В результате болезненные расстройства вследствие злоупотребления снотворными лекарственными веществами из класса F13 могут диагностироваться и как наркомания («этаминал натрия»), и как токсикомания («диазепам»).

3. Отнесение преступления к совершенному впервые является не столько вопросом факта, сколько юридической оценки уголовно-правовых отношений, возникших по вине лица. Преступление будет считаться таковым, если лицо ранее к уголовной ответственности не привлекалось, либо не осуждалось, либо истекли сроки давности

\footnotetext{
${ }^{3}$ Международная классификация болезней десятого пересмотра (МКБ-10). [Электронный ресурс]. -Режим доступа: http://aeli.altai. ru/conferenc/1999/turina.html.

${ }^{4}$ Большой медицинский энциклопедический словарь/Под ред. В.И. Бородулина. - Изд. 4-е, исправленное и дополненное. - М.: РИПОЛ классик, 2007. С. 640.

${ }^{5}$ Шабанов В.Б., Штакельберг О.Ю. Наркомании: патопсихология, клиника, реабилитация. Изд. 2-е, перераб. и доп. /Под ред. А.Я. Гриненко, - СПб.: Издательство «Лань», 2001. С.211.
} 


\section{Право и политика 5 (161) 2013}

привлечения его к уголовной ответственности, либо его судимость снята или погашена в установленном законом порядке, а также, если лицо не состоит под следствием или судом и не уклоняется от следствия и суда. ${ }^{6}$ Но при этом преступления должны быть предусмотрены только ч.1 ст. 228 УК (незаконные действия с наркотиками в крупном размере, совершенные без цели сбыта), ч.1 ст. 231 УК «Незаконное культивирование растений, содержащих наркотические средства или психотропные вещества либо их прекурсоры» и ст. 233 УК «Незаконная выдача либо подделка рецептов или иных документов, дающих право на получение наркотических средств или психотропных веществ». Законодательные ограничения на применение ст. 82.1 УК совершением конкретных видов преступлений порождают ряд вопросов, которые требуют отдельного рассмотрения.

Первый из них связан с возможностью расширительного толкования словосочетания «совершившему впервые преступление, предусмотренное...» из гипотезы ч.1 ст.82.1 УК. Как следует из его буквального смысла, лицо вправе рассчитывать на отсрочку отбывания наказания во всех случаях совершения любых преступлений, в том числе относящихся к сфере незаконного оборота наркотиков и даже при наличии рецидива преступлений (ст.18 УК), главное, чтобы эти преступления не относились к указанному перечню. То есть, неоднократные совершения сбыта наркотиков или хищения чужого имущества, которые предшествовали совершенному впервые, например, незаконному приобретению наркотиков, никакого уголовно-правового значения для применения предусмотренной ст. 82.1 УК отсрочки отбывания наказания иметь не должны.

Возможно, законодатель в данном случае вкладывал иной смысл, подразумевая, что до совершения преступлений из указанного перечня лицо вообще преступлений не совершало (в юридическом смысле). Думается, подобной многозначности можно было бы избежать, если бы редакция анализируемого словосочетания была, например, следующей: «совершившему впервые преступление, и это преступление предусмотрено...».

В любом случае, приобретение права на отсрочку отбывания наказания только при совершении одного из трех наркопреступлений противоречит положениям Стратегии, обусловившей возникновение указанных правомочий тяжестью совершенных наркопреступлений.

\footnotetext{
${ }^{6}$ Уголовное право. Общая часть: Учебник. Издание второе переработанное и дополненное / Под ред. доктора юридиче-ских наук, профессора Л.В. Иногамовой-Хегай, доктора юридических наук, профессора А.И. Рарога, доктора юриди-ческих наук, профессора А.И. Чучаева. - М.: Юридическая фирма «КОНТРАКТ»: ИНФРА-М, 2008. С.443-444.
}

Не включение в указанный перечень преступлений, предусмотренных 228.2 УК «Нарушение правил оборота наркотических средств или психотропных веществ», видимо, было обусловлено тем, что страдающее наркоманией лицо не может состоять в должности, связанной с оборотом наркотиков. Однако применительно к незаконной выдаче рецептов, дающих право на получение наркотиков (ст. 233 УК), подобная возможность не исключается.

В особенности вызывает сомнение кажущаяся неспособность страдающих наркоманией лиц склонять к потреблению наркотиков (ч.1 ст. 230 УК), если по единодушному мнению криминологов и правоприменителей, один наркоман приобщает к их потреблению («заражает») 10-15 человек. Поэтому отказ в праве на обязательное лечение от наркомании как альтернативу отбывания наказания для данной категории «наркоинфицированных» лиц представляется неоправданным.

Не могут рассчитывать на отсрочку отбывания наказания по анализируемым основаниям больные наркоманией, осужденные за организацию либо содержание притонов для потребления наркотиков (ч.1 ст. 232 УК), несмотря на то, что для подобных наркопреступников во многом характерно предоставление помещений для потребления наркотиков в расчете на их безвозмездное получение.

Касаясь преступлений, связанных с незаконным оборотом сильнодействующих или ядовитых веществ (ст. 234 УК), то они в строгом смысле наркопреступлениями не являются. К тому же лица, страдающие болезненной зависимостью от употребления этих веществ, считаются больными токсикоманией, и потому не вправе рассчитывать на предусмотренную ст.82.1 УК отсрочку отбывания наказания. Однако в данном случае следует учитывать тот факт, что ряд сильнодействующих веществ по нормам Конвенции ООН 1971 г. относятся к психотропным веществам («хлордиазепоксид»), опасность которых для здоровья населения определена международно-правовым актом высшей юридической силы. Кроме того, относительная доступность сильнодействующих лекарственных веществ и отсутствие уголовной ответственности за их незаконные приобретение и хранение в личных целях, создают страдающим наркоманией благоприятную возможность заменять ими привычные наркотики или использовать в качестве дешевых прекурсоров («эфедрин») для изготовления других наркотиков.

Не подпадают под действие ст. 82.1 УК больные наркоманией, осужденные за сбыт наркотиков (ст.228.1 УК) и другие тяжкие и особо тяжкие наркопреступления. Если исходить из формальной тяжести совершенного общественно опасного деяния, логика законодательного решения, вроде бы, очевидна. Сомнение в данной части 
обусловливаются тем фактом, что во многих случаях сбытчики наркотиков и их приобретатели являются наркозависимыми. Но поскольку приобретатель наркотиков в уголовном судопроизводстве выступает в качестве свидетеля общественно-опасных действий сбытчика наркотиков, его заболевание наркоманией никакого уголовно-правового значения не имеет. Получается, что в целях снижения уровня наркопотребления одна часть наркозависимых используется правоприменителем для изобличения преступной деятельности других наркозависимых, и при этом последние вправе рассчитывать на применение в отношении них обязательного лечения от наркомании в порядке, предусмотренном ст. 73 или 82.1 УК. Однако больные наркоманией приобретатели наркотиков, благодаря действиям которых изобличаются больные наркоманией сбытчики наркотиков, никаким обязательным мероприятиям по избавлению от наркозависимости не подвергаются, что фактически означает продолжение ими употребления наркотиков, только несколько легитимированное. В данном случае больные наркоманией приобретатели наркотиков как бы приносятся в жертву борьбы с незаконным оборотом наркотиком. Ведь если излечение от наркомании наркопреступников урегулировано рамками уголовно-правовых институтов, то больные наркоманией их изобличители, также являющиеся обязательными участниками уголовного судопроизводства, заведомо поставлены в худшее условия, поскольку лишены законодательно обеспеченной поддержки со стороны государства в избавлении от наркозависимости.

Вообще ситуация, когда государство принимает на себя обязательства по контролю над излечением наркозависимости только в случаях, когда больной наркоманией совершит преступление впервые, и оно будет относиться к наркопреступлений из числа 3 утвержденных, представляется недопустимой. Ведь никем не подвергается сомнению, что наркозависимость выступает медико-биологической причиной совершения, по меньшей мере, посягательств на собственность в целях добывания средств для приобретения наркотиков. И коль скоро Генеральной целью Стратегии является существенное сокращение немедицинского потребления наркотиков (п.4), то лишение данной категории наркозависимых права подвергнуться обязательному лечению в порядке ст.82.1 УК только потому, что совершенное ими преступление не из привилегированного списка, вряд ли способно обеспечить снижение уровня наркопотребления.

4. Изъявление желания добровольно пройти курс лечения от наркомании, а также медико-социальную реабилитацию выражается в письменном заявлении лицу, производящего предварительное расследование, о согласии принять указанные обязательства как условие отсрочки отбывания наказания в виде лишения свободы.
Подводя итог изложенному считаем, что возможность назначения страдающим химической зависимостью обязательного лечения должна обусловливаться не классом злоупотребляемого ПАВ или видом и тяжестью совершенного преступления, а только медицинскими показаниями. Тем более, что потенциал применения данных обязательных мер, определяемый числом лиц, совершивших преступления в состоянии наркотического опьянении, в 2009 г.составил 6390 человек (при среднем значении за период с 2003 г. 6694 человек), или в 6 раз больше числа подвергнутых обязанности пройти курс лечения от наркомании в порядке ст. 73 УК РФ.

\section{Библиография:}

1. Большой медицинский энциклопедический словарь/ Под ред. В.И. Бородулина. - Изд. 4-е, исправленное и дополненное. - М.: РИПОЛ классик, 2007.

2. Международная классификация болезней десятого пересмотра (МКБ-10). [Электронный ресурс]. - Режим доступа: http://aeli.altai.ru/conferenc/1999/ turina.html.

3. Шабанов В.Б., Штакельберг О.Ю. Наркомании: патопсихология, клиника, реабилитация. Изд. 2-е, перераб. и доп. /Под ред. А.Я. Гриненко, - СПб.: Издательство «Лань», 2001.

4. Уголовное право. Общая часть: Учебник. Издание второе переработанное и дополненное / Под ред. доктора юридиче-ских наук, профессора Л.В. Иногамовой-Хегай, доктора юридических наук, профессора А.И. Рарога, доктора юриди-ческих наук, профессора А.И. Чучаева. - М.: Юридическая фирма «КОНТРАКТ»: ИНФРА-М, 2008. - 560 с.

5. Постановление Правительства Российской Федерации от 22.02.2012 г. №144 «О внесении изменений в некоторые акты Правительства Российской Федерации в связи с совершенствованием контроля за оборотом наркотических средств, психотропных веществ и их прекурсоров» //РГ. 6.03.2012 г. №48.

6. Данные Судебного департамента при Верховном Суде РФ. [Электронный ресурс]. - Режим доступа: http://crimpravo.ru/page/sudstatistic/.

\section{References (transliteration):}

1. V.I. Borodulin Bol'shoy meditsinskiy entsiklopedicheskiy slovar'/Pod red. V.I. Borodulina. - Izd. 4-e, ispravlennoe i dopolnennoe. - M.: RIPOL klassik, 2007.

2. Mezhdunarodnaya klassifikatsiya bolezney desyatogo peresmotra (MKB-10). [Elektronnyy resurs]. - Rezhim dostupa: http://aeli.altai.ru/conferenc/1999/turina.html. 
DOI: 10.7256/1811-9018.2013.05.7

\section{Право и политика 5 (161) 2013}

3. Shabanov V.B., Shtakel'berg O.Yu. Narkomanii: patopsikhologiya, klinika, reabilitatsiya. Izd. 2-e, pererab. i dop. / Pod red. A.Ya. Grinenko, - SPb.: Izdatel'stvo «Lan'», 2001.

4. L.V. Inogamovoy-Khegay. Ugolovnoe pravo. Obshchaya chast': Uchebnik. Izdanie vtoroe pererabotannoe i dopol- nennoe / Pod red. doktora yuridiche-skikh nauk, professora L.V. Inogamovoy-Khegay, doktora yuridicheskikh nauk, professora A.I. Raroga, doktora yuridi-cheskikh nauk, professora A.I. Chuchaeva. — M.: Yuridicheskaya firma «KONTRAKT»: INFRA-M, 2008. - $560 \mathrm{~s}$. 